\title{
STUDI META-ANALISIS \\ HUBUNGAN ANTARA PENERAPAN TOTAL QUALITY MANAGEMENT (TQM) DAN KINERJA ORGANISASI
}

\author{
Novi Marlyana ${ }^{1}$, Avin Fadilla Helmi ${ }^{2}$, Alva Edy Tontowi ${ }^{1}$, Hari Agung Yuniarto ${ }^{1}$ \\ ${ }^{1}$ Jurusan Teknik Mesin dan Industri, Fakultas Teknik Mesin, Universitas Gadjah Mada \\ ${ }^{2}$ Fakultas Psikologi, Universitas Gadjah Mada \\ novi.unissula@gmail.com
}

\begin{abstract}
ABSTRAK
Kegunaan meta analisis dalam studi ini adalah untuk menjelaskan dan membuktikan hubungan keterkaitan antara penerapan metode peningkatan kualitas yaitu TQM (Total Quality Management) terhadap peningkatan kinerja organisasi. Artikel-artikel yang digunakan dalam meta analisis ini dikumpulkan melalui electronic journal database antara tahun 2003-2014. Terdapat 12 jurnal yang dapat dikaji secara kuantitatif. Hasilnya menunjukkan bahwa koefisien korelasi populasi setelah dikoreksi dengan jumlah sampel atau ř sebesar 0,622. Mengacu pada interval kepercayaan sebesar 95\%, batas penerimaannya antara 0,359 $<\check{r}<0,885$. Dengan demikian hasil perhitungan $\check{r}$ sebesar 0,622 berada pada batas penerimaan. Berdasarkan hasil ini maka dapat disimpulkan bahwa hipotesis yang menyatakan adanya hubungan antara TQM dan kinerja organisasi dapat diterima.
\end{abstract}

Kata kunci: meta analisis, kualitas, TQM, kinerja organisasi.

\section{PENDAHULUAN}

Total Quality Management (TQM) atau Manajemen Kualitas Total merupakan sebuah filosofi dan sekumpulan prinsip panduan yang menunjukkan dasar bagi peningkatan organisasi secara berkelanjutan. Besterfield et al (1999) menyatakan bahwa TQM merupakan penerapan yang menggabungkan prinsip manajemen, metode kuantitatif, dan sumber daya manusia guna meningkatkan semua proses dalam sebuah organisasi dan memenuhi kebutuhan konsumen pada saat ini dan masa yang akan datang [1]. Selain itu TQM mampu memainkan peran penting dalam membantu perusahaan untuk menjadi lebih kompetitif dalam ekonomi global.

Brah dan Lim (2006), Ou et al (2007) dan Zadry (2005) menyatakan bahwa kepuasan pelanggan merupakan inti dari TQM [2]. Fokus pada pelanggan secara jelas merupakan sebuah pendekatan proaktif dalam mengidentifikasi psikologis, emosional, dan kebutuhan bisnis pelanggan, dan pemenuhannya. Komunikasi yang terbuka, dan keterlibatan pelanggan dalam pengambilan keputusan meningkatkan keterkaitan bersama. Inovasi produk yang efisien, proses pengiriman dan pelayanan, pemberdayaan kontak personil, dan manajemen hubungan pelanggan menggerakkan kepuasan pelanggan. Suatu mekanisme yang efisien didasarkan pada respon terpadu oleh semua orang dalam organisasi adalah sangat penting untuk mengantisipasi dan memenuhi perubahan kebutuhan pelanggan. Pemantauan kebutuhan pelanggan secara konstan sangat penting untuk memulai strategi responsif guna memenuhi daya saing. Fokus pada pelanggan merupakan proses yang berkesinambungan dan sebutan bagi pendekatan yang diadakan untuk mencapai keuntungan strategis.

Abdullah et al (2008) menyatakan bahwa kinerja organisasi akan meningkat ketika perusahaan menjalankan penerapan peningkatan kualitas yang lebih baik [3]. Abusa \& Gibson [3] menjelaskan bahwa penelitian terkait hubungan antara penerapan TQM dan kinerja organisasi merupakan penelitian yang saat ini menjadi perhatian dalam berbagai literatur tentang TQM. Kinerja organisasi (organizational performance) diukur melalui: kepuasan konsumen, tingkat cacat, moral pekerja, peningkatan produksi, pertumbuhan penjualan, pertumbuhan ekspor, pertumbuhan keuntungan, dan keseluruhan posisi persaingan. Sementara elemen dalam TQM meliputi: komitmen manajemen atas, fokus 
kepada konsumen, manajemen kualitas dari pemasok, manajemen sumber daya manusia, peningkatan berkelanjutan, dan manajemen proses [3].

Lebih lanjut Plessis dan Beer (2011), Wang (2011), Wei dan Qui (2009) menjelaskan bahwa kompetensi manajerial mengacu pada keterampilan, kemampuan, sikap, dan perilaku manajer dalam konteks organisasi. Gabungan yang seimbang dari atribut-atribut ini mensinergikan pengembangan pribadi, mendorong dan fokus organisasi 'pelanggan' karyawan, dan menghasilkan kinerja yang unggul. Terdapat konsensus bahwa kompetensi yang dibutuhkan untuk mengelola lingkungan TQM adalah inovasi dan kreativitas, kemampuan beradaptasi, fokus pada pelanggan, pembelajaran berkelanjutan dan rasa ingin tahu, kemampuan interpersonal dan komunikasi, orientasi perubahan, tim building, orientasi hasil, komitmen untuk perbaikan terus-menerus, menginspirasi bawahan, secara efektif mengelola proses fungsional, dan pekerjaan, serta keahlian teknis. Terdapat bukti kuat dalam literatur bahwa penerapan dari kompetensi-kompetensi tersebut memiliki hubungan yang kuat dengan kinerja organisasi [2].

Sebuah studi meta analis telah dilakukan oleh Jitpaiboon \& Rao [1] terkait hubungan positif antara penerapan TQM terhadap kinerja internal dan eksternal. Studi yang dilakukan juga menunjukkan hubungan langsung antara penerapan TQM dan kinerja organisasi. Penerapan TQM yang berbeda akan mempengaruhi perbedaan dalam kinerja organisasi. Studi meta analisis yang dilakukan tersebut berasal dari 50 artikel dari 16 jurnal dan 2 prosiding konferensi yang dipublikasikan antara tahun 1989 hingga 2002. Sementara disebutkan pula bahwa tidak ada artikel terkait dengan TQM yang dipublikasikan antara 2003-2005 yang memiliki nilai $\alpha$. Pada kesimpulannya, Jitpaiboon \& Rao [1] mengusulkan bahwa peneliti tentang TQM seharusnya menyertakan karakteristik desain dalam rangka mencapai suatu skala reliabilitas yang tinggi.

Pada studi meta analisis yang saat ini penulis lakukan adalah melanjutkan studi terkait hubungan antara penerapan TQM dan kinerja organisasi dengan menambahkan artikel lain yang dipublikasikan antara tahun 2003 hingga tahun 2014. Berdasarkan kajian literatur maka kerangka konsep dalam penelitian ini adalah sebagai berikut:

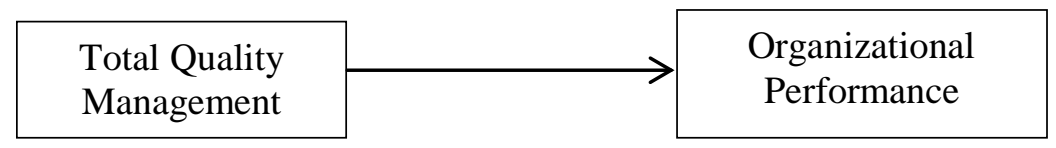

Gambar 1. Kerangka hubungan antara TQM dan kinerja organisasi

Artikel diperoleh dari pencarian melalui database elektronik, meliputi: Emerald, ScienceDirect, dan EBSCOhost. Kata kunci yang digunakan adalah "Total Quality Management”, "Organizational Performance”, "quality”, dan "performance”. Seleksi artikel dibatasi pada artikel berbahasa Inggris pada rentang waktu tahun 2003 hingga tahun 2014. Pencarian artikel awal berhasil mengidentifikasi sebanyak 157 artikel yang mengkhususkan pada penerapan TQM maupun kinerja organisasi. Kemudian dari artikel awal tersebut disaring dan diidentifikasi sehingga menghasilkan sebanyak 12 artikel yang merupakan penelitian/studi empiris.

\section{LANDASAN TEORI}

\section{A. Meta Analisis}

Meta-analisis merupakan studi dengan cara menganalisis data yang berasal dari studi primer. Sugiyanto (2004) menyatakan bahwa hasil analisis studi primer dipakai sebagai dasar untuk menerima atau mendukung hipotesis atau menolak/menggugurkan hipotesis yang diajukan oleh beberapa peneliti [4].

Meta analisis merupakan suatu teknik yang ditujukan untuk menganalisis kembali hasil-hasil penelitian yang diolah secara statistik berdasarkan pengumpulan data primer. Hal ini dilakukan untuk mengkaji keajegan atau ketidakajegan hasil penelitian yang 
disebabkan semakin banyaknya replikasi atau verifikasi penelitian, yang seringkali justru memperbesar terjadinya variasi hasil penelitian [4].

Sugiyanto (2004) menjelaskan bahwa dalam upaya melakukan sintesa dari beberapa penelitian, terlebih dahulu dilakukan koreksi terhadap artefak atau ketidaksempurnaan penelitian [4]. Hunter \& Schmidt [5] menyebutkan sedikitnya ada 11 artefak yaitu:

1. Kesalahan pengambilan sampel (sampling error).

2. Kesalahan pengukuran pada variabel dependen (error of measurement in the dependent variable).

3. Kesalahan pengukuran pada variabel independen (error of measurement in the independent variable).

4. Dikotomi variabel dependen (dichotomization of a continuous dependent variable)

5. Dikotomi variabel independen (dichotomization of a continuous independent variable).

6. Variasi rentangan dalam variabel independen (range variation in the independent variable).

7. Artefak atrisi (attrition artifacts).

8. Ketidaksempurnaan validitas konstruk pada variabel dependen (deviation from perfect construct validity in the dependent variable).

9. Ketidaksempurnaan validitas konstruk pada variabel independen (deviation from perfect construct validity in the independent variable).

10. Kesalahan pelaporan atau transkripsi (reporting or transcriptional error).

11. Varians yang disebabkan oleh faktor luar (variance due to extraneous factors that affect the relationship).

\section{B. Total Quality Management (TQM) dan Kinerja Organisasi}

Hackman dan Wageman (1995) menjelaskan bahwa ide utama dari total quality management (TQM) diperkenalkan pada pertengahan tahun 1980 oleh W. Edwards Deming, Joseph Juran, dan Kaoru Ishikawa [6]. Menurut Waldman (1994) bahwa TQM merupakan strategi organisasi yang terintegrasi guna meningkatkan kualitas produk dan jasanya [6].

Juran (1988) dan Feigenbaum (1991) menyatakan bahwa TQM merupakan sebuah sumber potensial untuk mencapai tujuannya dalam memproduksi nilai, melalui peningkatan pemahaman kebutuhan konsumen, peningkatan kepuasan konsumen, peningkatan komunikasi internal, pemecahan masalah yang semakin baik, komitmen dan motivasi pekerja semakin baik, hubungan dengan pemasok yang semakin kuat, kesalahan yang semakin kecil dan mengurangi cacat [7].

Sejumlah studi telah dilakukan dalam menentukan hubungan antara penerapan TQM dan kinerja organisasi telah disebutkan sejak penelitian Gavin (1988) menemukan bahwa terdapat lebih banyak penelitian penting yang menghubungkan penerapan kualitas dengan kinerja [8]. Penelitian terkait hubungan antara TQM dan kinerja organisasi juga dilakukan oleh Fotopoulos dan Psomas [9]. Penelitian ini menunjukkan bahwa faktorfaktor pada TQM memberikan pengaruh terhadap kinerja organisasi. Faktor-faktor tersebut meliputi: penerapan kualitas dari manajemen puncak, keterlibatan karyawan, fokus pada konsumen, manajemen kualitas data dan proses, dan penggunaan alat-alat dan teknik kualitas. Diantara faktor-faktor tersebut maka penggunaan alat-alat dan teknik kualitas memiliki hubungan yang lebih signifikan dalam memberikan pengaruh terhadap kinerja organisasi.

\section{METODOLOGI PENELITIAN}

Penelitian yang dilakukan melalui prosedur sebagai berikut:

1. Formulasi masalah

2. Pengumpulan data dari studi primer 
Pengumpulan data dari jurnal elektronik melalui www.lib.ugm.ac.id. Pengumpulan data awal dimulai dengan mencari artikel yang terkait dengan TQM dan kinerja organisasi. Kemudian setelah itu diteliti artikel yang memiliki nilai $\alpha$.

3. Evaluasi data

Dari hasil penelitian yang diperoleh dapat diketahui harga F. Harga F tersebut perlu dilakukan transformasi ke dalam harga t, $\mathrm{r}$, dan $\mathrm{d}$.

4. Analisis dan interpretasi data

Studi meta analisis ini mengikuti tahapan analisis dan interpretasi data penelitian sebagai berikut:

a. Transformasi nilai/koefisien $\mathrm{F}$ atau $\mathrm{t}$ ke $\mathrm{r}$.

b. Bare-bones meta analisis, yaitu suatu metode analisis yang digunakan untuk mengetahui koreksi kesalahan sampel, yang mana pada tahap ini dilakukan dengan cara:

- Menghitung rerata korelasi populasi

- Menghitung varians $r_{x y}\left(\sigma^{2} r\right)$

- Menghitung varians kesalahan pengambilan sampel $\left(\sigma^{2} e\right)$

- Dampak pengambilan sampel

c. Koreksi kesalahan pengukuran

Pada tahap ini dilakukan dengan cara:

- Menghitung rerata reliabilitas alat ukur

- Menghitung koreksi kesalahan pengukuran

- Jumlah koefisien kuadrat variasi (V)

- Varians yang mengacu variasi artifak

- Varians korelasi sesungguhnya

- Interval kepercayaan

- Dampak variasi reliabilitas

\section{HASIL DAN PEMBAHASAN}

Proses pencarian literatur melalui database elektronik mengidentifikasi sebanyak 157 artikel yang terkait dengan TQM maupun kinerja organisasi. Kemudian dilanjutkan dengan menyaring artikel yang menjelaskan hubungan antara TQM dan kinerja organisasi dan diperoleh sebanyak 65 artikel. Selanjutnya diidentifikasi sebanyak 58 artikel yang menjelaskan Critical Success Factors (CSFs) dari TQM di perusahaan atau UKM. Pada akhirnya diperoleh sebanyak 12 artikel yang bisa diolah karena merupakan penelitian empiris. Proses yang dijalankan dapat digambarkan sebagai berikut:

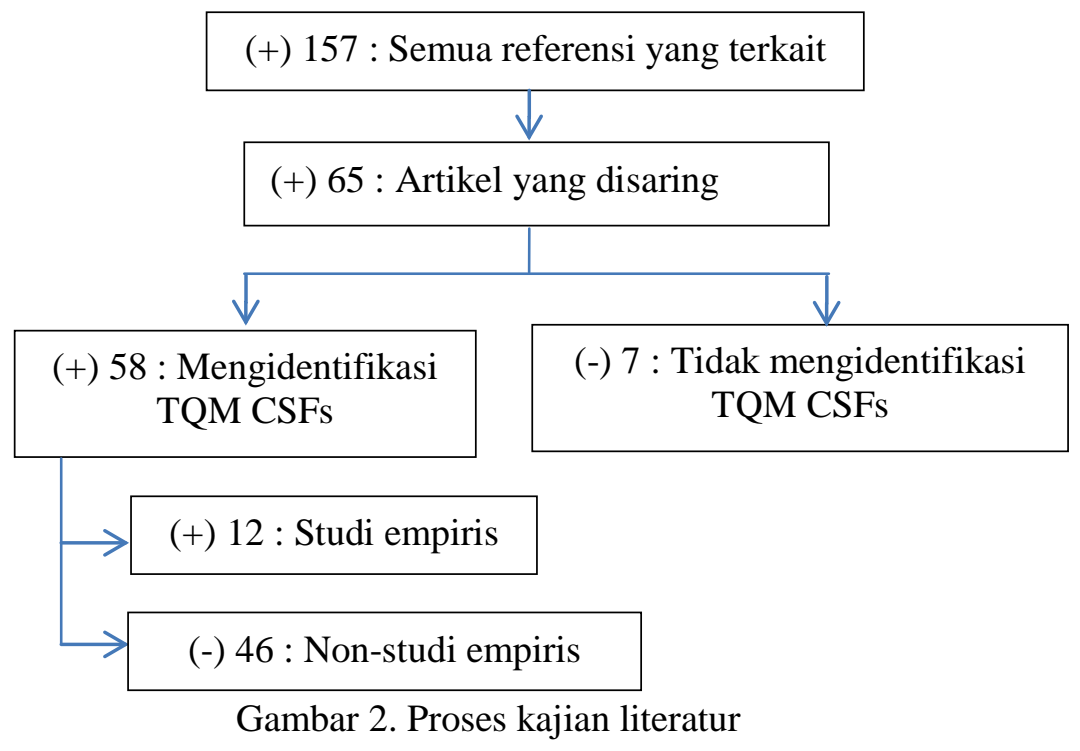


A. Analisa Data

1. Karakteristik Sampel Penelitian

Berikut tabel 1 menunjukkan karakteristik sampel yang terdiri dari tahun penelitian yang berkisar antara tahun 2003-2014, nama peneliti, jumlah sampel, karakteristik sampel dan negara tempat objek penelitian dilakukan.

Tabel 1. Karakteristik sampel penelitian

\begin{tabular}{cclclc}
\hline \multirow{2}{*}{ No } & \multirow{2}{*}{ Tahun } & \multicolumn{2}{c}{ Peneliti } & \multicolumn{3}{c}{ Sampel } \\
\cline { 3 - 5 } & & & Jumlah & Karakteristik & Negara \\
\hline 1 & 2003 & Hasan [10] & 109 & Perusahaan & Australia \\
2 & 2003 & Sohail [8] & 80 & Perusahaan & Malaysia \\
3 & 2006 & Joiner [6] & 84 & Perusahaan & Australia \\
4 & 2006 & Demirbag [11] & 141 & UKM manufaktur & Turki \\
5 & 2008 & Jung [12] & 230 & Perusahaan & Mexico \\
6 & 2009 & Fotopoulos [9] & 370 & Perusahaan & Yunani \\
7 & 2011 & Khan [2] & 250 & Perusahaan & Pakistan \\
8 & 2011 & Koc [7] & 111 & UKM manufaktur & Turki \\
9 & 2011 & Valmohammadi [13] & 65 & UKM manufaktur & Iran \\
10 & 2012 & Samarakoon [14] & 150 & UKM manufaktur & Srilanka \\
11 & 2013 & Abusa [3] & 56 & Perusahaan & Libya \\
12 & 2013 & Talib [15] & 172 & Perusahaan & India \\
\hline \multicolumn{7}{c}{ Total } & 1818 & & \\
\hline
\end{tabular}

2. Analisis data

a. Transformasi Nilai $\mathrm{F}$ atau $\mathrm{t}$ ke $\mathrm{r}_{\mathrm{xy}}$

Dari 157 studi yang telah terkumpul, ternyata tinggal 12 studi yang dapat menghasilkan nilai $\mathrm{F}$ atau $\mathrm{t}$. Untuk itu nilai $\mathrm{F}$ atau $\mathrm{t}$ ini perlu ditransformasikan ke nilai $r_{x y}$. Menurut Hunter dan Schmidt [5], rumus yang digunakan untuk mentransformasikan nilai $\mathrm{F}$ atau $\mathrm{t}$ tersebut adalah:

$$
\begin{aligned}
& t=\sqrt{F} \\
& r_{x y}=\frac{t}{\sqrt{t^{2}+(N-2)}}
\end{aligned}
$$

b. Bare-Bone Meta Analysis (Analisis Koreksi kesalahan pengambilan sampel) Menurut Hunter dan Schmidt [5] jika korelasi populasi diasumsikan konstan di antara beberapa studi, maka estimasi terbaik dari korelasi bukanlah rerata sederhana dari korelasi beberapa studi melainkan merupakan rerata yang dibobot untuk masing-masing korelasi yaitu dibagi dengan jumlah sampel dalam studi. Estimasi terbaik untuk korelasi populasi adalah mengikuti rumus berikut ini:

$$
\check{r}=\sum\left(N_{i} r_{i}\right) / \sum N_{i}
$$

$r_{\mathrm{i}}$ adalah korelasi xy pada studi i dan $\mathrm{N}_{\mathrm{i}}$ adalah jumlah sampel pada studi i. Tahap berikutnya adalah mengubah nilai $r_{i}$ atau $r_{x y}$ pada masing-masing studi untuk mendapatkan rerata korelasi populasi, seperti yang disajikan pada tabel 2. 
Tabel 2. Hasil Perhitungan Transformasi Nilai $\mathrm{F}$ atau $\mathrm{t}$ ke $\mathrm{r}_{\mathrm{xy}}$

\begin{tabular}{ccccccc}
\hline No studi & Cahun & Penulis & $\mathbf{N}$ & $\mathbf{F}$ & $\mathbf{t}$ & $\mathbf{r}_{\mathbf{x y}}$ \\
\hline 1 & 2003 & Hasan & 109 & - & - & 0,603 \\
2 & 2003 & Sohail & 80 & - & 3,44 & 0,363 \\
3 & 2006 & Joiner & 84 & - & - & 0,63 \\
4 & 2006 & Demirbag & 141 & - & - & 0,668 \\
5 & 2008 & Jung & 230 & - & - & 0,62 \\
6 & 2009 & Fotopoulos & 370 & - & - & 0,657 \\
7 & 2011 & Khan & 250 & 640,079 & - & 0,797 \\
8 & 2011 & Koc & 111 & 7,703 & 25,3 & 0,394 \\
9 & 2011 & Valmohammadi & 65 & - & - & 0,512 \\
10 & 2012 & Samarakoon & 150 & - & - & 0,519 \\
11 & 2013 & Abusa & 56 & 4,44 & 7,391 & 0,276 \\
12 & 2013 & Talib & 172 & 16,538 & 2,107 & 0,779 \\
\hline
\end{tabular}

Tabel 3. Koreksi Kesalahan Sampling

\begin{tabular}{cccc}
\hline No studi & $\mathbf{N}$ & $\mathbf{r}_{\mathbf{x y}}$ & $\mathbf{N ~ x ~}_{\mathbf{x v}}$ \\
\hline 1 & 109 & 0,603 & 65,727 \\
2 & 80 & 0,363 & 73,704 \\
3 & 84 & 0,63 & 52,92 \\
4 & 141 & 0,668 & 94,188 \\
5 & 230 & 0,62 & 142,6 \\
6 & 370 & 0,657 & 243,09 \\
7 & 250 & 0,797 & 199,25 \\
8 & 111 & 0,394 & 43,734 \\
9 & 65 & 0,512 & 33,28 \\
10 & 150 & 0,519 & 77,85 \\
11 & 56 & 0,276 & 15,456 \\
12 & 172 & 0,779 & 133,988 \\
\hline Jumlah & 1818 & 6,818 & 1131,123 \\
\hline Rerata & & 0,622 & \\
\hline
\end{tabular}

Rerata korelasi populasi setelah dikoreksi dengan jumlah sampel atau $\check{r}=0,622$.

Tahap berikutnya adalah menghitung varians $\mathrm{r}_{\mathrm{xy}}$ atau $\delta^{2} r$ dengan menggunakan rumus sebagai berikut:

$$
\sigma^{2} r=\sum\left[N_{i}\left(r_{i}-\check{r}\right)^{2}\right] / \sum N_{i}
$$

Hasil perhitungan varians $\mathrm{r}_{\mathrm{xy}}$ dapat dilihat pada tabel 4 .

Berdasarkan hasil perhitungan yang telah tertera pada tabel 4 diatas, diketahui bahwa varians $\mathrm{r}_{\mathrm{xy}}$ atau $\delta^{2} r$ adalah sebesar 0,018 .

Tahap selanjutnya adalah menghitung varians kesalahan pengambilan sampel. Seperti telah diketahui bahwa varians $\mathrm{r}_{\mathrm{xy}}$ adalah 0,018 itu merupakan campuran dari dua hal, yaitu: variasi dalam korelasi populasi dan variasi dalam korelasi sampel yang dihasilkan oleh kesalahan sampling. Menurut Hunter dan Schmidt [5] estimasi varians dalam korelasi populasi dapat diperoleh hanya dengan mengkoreksi varians $\sigma^{2} \mathrm{r}$ yang teramati untuk kesalahan sampling. Varians kesalahan pengambilan sampel dapat dihitung dengan menggunakan rumus sebagai berikut:

$$
\sigma^{2} e=\left(1-\check{r}^{2}\right)^{2} /(\breve{N}-1)
$$


Tabel 4. Varians $r_{\mathrm{xy}}$

\begin{tabular}{|c|c|c|c|c|c|}
\hline No studi & $\mathbf{N}$ & $\mathbf{r}_{\mathrm{xy}} / \mathbf{r}_{\mathrm{i}}$ & $\left(r_{i}-\check{r}\right)$ & $\left(\mathrm{r}_{\mathrm{i}}-\check{r}\right)^{2}$ & $\mathbf{N}\left(\mathbf{r}_{\mathrm{i}}-\check{r}\right)$ \\
\hline 1 & 109 & 0,603 & $-0,012$ & 0,000144 & 0,015696 \\
\hline 2 & 80 & 0,363 & $-0,252$ & 0,063504 & 5,08032 \\
\hline 3 & 84 & 0,63 & 0,015 & 0,000225 & 0,0189 \\
\hline 4 & 141 & 0,668 & 0,053 & 0,002809 & 0,396069 \\
\hline 5 & 230 & 0,62 & 0,005 & 0,000025 & 0,00575 \\
\hline 6 & 370 & 0,657 & 0,042 & 0,001764 & 0,65268 \\
\hline 7 & 250 & 0,797 & 0,182 & 0,033124 & 8,281 \\
\hline 8 & 111 & 0,394 & $-0,221$ & 0,048841 & 5,421351 \\
\hline 9 & 65 & 0,512 & $-0,103$ & 0,010609 & 0,689585 \\
\hline 10 & 150 & 0,519 & $-0,096$ & 0,009216 & 1,3824 \\
\hline 11 & 56 & 0,276 & $-0,339$ & 0,114921 & 6,435576 \\
\hline 12 & 172 & 0,779 & 0,164 & 0,026896 & 4,626112 \\
\hline Jumlah & 1818 & & & & 33,00544 \\
\hline Rerata & 151,5 & & & & 0,018155 \\
\hline SD & 92,371 & & & & 2,996716 \\
\hline
\end{tabular}

Berdasarkan nilai $\check{r}$ yang telah diperoleh yaitu sebesar 0,622 dan rerata jumlah sampel $\breve{N}=151,5$, maka varians kesalahan pengambilan sampel pada studi meta analisis ini adalah:

$$
\delta^{2} e=\frac{\left(1-0,622^{2}\right)^{2}}{151,5-1}=0,00249
$$

Jadi varians kesalahan pengambilan sampelnya adalah sebesar $\delta^{2} e=0,00249$.

Langkah berikutnya menghitung varians korelasi populasi atau varians yang sesungguhnya. Varians korelasi populasi merupakan varians yang dikoreksi yaitu, varians $r_{x y}$ dikurangi dengan varians kesalahan pengambilan sampel. Dalam hal ini dapat dihitung dengan menggunakan rumus:

$$
\delta^{2} p=\delta^{2} r-\delta^{2} e=0,018-0,00249=0,01551
$$

Setelah diketahui varians korelasi populasi, langkah selanjutnya adalah menentukan interval kepercayaan. Jika korelasi populasi setelah dikoreksi dengan jumlah sampel $(\check{r})$ memiliki distribusi normal, maka interval kepercayaan dapat ditentukan berdasarkan rumus berikut:

$$
\begin{gathered}
p=\check{r} \pm 1.96 S D=\check{r} \pm 1.96 x \sqrt{\sigma^{2} r} \\
p=0,622 \pm 1.96 x \sqrt{0,018}=0,622 \pm 0,263 \\
\text { Pbawah }_{\text {bat }}=0,359 \text { dan } \text { patas }_{\text {ata }}=0,885
\end{gathered}
$$

Jadi interval kepercayaan 0,359 $<\check{r}<0,885$

Langkah selanjutnya, menghitung dampak kesalahan pengambilan sampel dengan cara sebagai berikut:

$$
\left(\delta^{2} e / \delta^{2} r\right) \times 100 \%=(0,00249 / 0,018) x 100 \%=13,8 \%
$$

c. Koreksi kesalahan pengukuran

Koreksi artefak selain kesalahan pengambilan sampel adalah koreksi kesalahan pengukuran. Pada studi yang berkaitan dengan keterkaitan antara TQM dan kinerja organisasi yang digunakan dalam meta analisis ini, semuanya merupakan studi dengan pendekatan survei. Untuk membuat estimasi kesalahan pengukuran, maka disusun lembar kerja seperti tabel 5 berikut ini: 
Tabel 5. Lembar Kerja Estimasi Kesalahan Pengukuran

\begin{tabular}{cccclc}
\hline No studi & $\mathbf{N}$ & $\mathbf{r}_{\mathbf{x y}}$ & $\mathbf{r}_{\mathbf{y y}}$ & $\mathbf{a}\left(\sqrt{\boldsymbol{r}_{\mathbf{y y}}}\right)$ & $\mathbf{N} \mathbf{x} \mathbf{r}_{\mathbf{x y}}$ \\
\hline 1 & 109 & 0,603 & - & - & 65,727 \\
2 & 80 & 0,363 & 0,9213 & 0,959 & 73,704 \\
3 & 84 & 0,63 & - & - & 52,92 \\
4 & 141 & 0,668 & 0,668 & 0,817 & 94,188 \\
5 & 230 & 0,62 & - & - & 142,6 \\
6 & 370 & 0,657 & 0,863 & 0,929 & 243,09 \\
7 & 250 & 0,797 & 0,798 & 0,893 & 199,25 \\
8 & 111 & 0,394 & - & - & 43,734 \\
9 & 65 & 0,512 & 0,89 & 0,943 & 33,28 \\
10 & 150 & 0,519 & 0,868 & 0,932 & 77,85 \\
11 & 56 & 0,276 & - & 0 & 15,456 \\
12 & 172 & 0,779 & 0,879 & 0,938 & 133,988 \\
\hline Jumlah & 1818 & 6,818 & 5,887 & 6,412 & 1131,123 \\
\hline Rerata & 151,5 & 0,568 & 0,841 & 0,916 & 0,622 \\
\hline SD & 92,37 & 0,16 & 0,085 & 0,048 & 71,74 \\
\hline
\end{tabular}

\section{Koreksi kesalahan pengukuran $\mathbf{Y}$}

Karena dalam studi ini koefisien reliabilitas $\left(\mathrm{r}_{\mathrm{yy}}\right)$ hanya ada 1 (satu) yakni pada variabel tergantung saja, maka rerata kesalahan pengukurannya hanya difokuskan pada variabel Y. Rumus yang digunakan untuk menghitungnya adalah:

$$
\tilde{A}=\operatorname{Ave}(a)=0,916 \text {. }
$$

Keterangan:

$\tilde{A}=$ rerata koreksi kesalahan pengukuran

$(a)=$ akar kuadrat koefisien reliabilitas $\mathrm{r}_{\mathrm{yy}}$ $\operatorname{Ave}(a)=$ rerata $(\mathrm{a})$

Selanjutnya penghitungan korelasi populasi yang sesungguhnya setelah dikoreksi dengan kesalahan pengukuran, digunakan rumus sebagai berikut:

$$
p=\operatorname{Ave}\left(p_{i}\right)=\frac{\text { Ave } \check{r}}{\tilde{A}}=0,622 / 0,916=0,679
$$

Keterangan:

Ave $\check{r}$ = rerata sesungguhnya dari korelasi $\mathrm{r}_{\mathrm{xy}}$ $\tilde{A}=$ rerata koreksi kesalahan pengukuran

Korelasi populasi sesungguhnya setelah dikoreksi oleh kesalahan pengukuran pada variabel dependen adalah sebesar 0,679.

Langkah berikutnya, menghitung jumlah koefisien kuadrat variasi (V) dengan menggunakan rumus sebagai berikut:

$$
\mathrm{V}=\mathrm{SD}^{2}(\mathrm{a}) / \operatorname{Ave}^{2}(\mathrm{a})=(0,048)^{2} /(0,916)^{2}=0,002746
$$

Kemudian menghitung varians yang mengacu variasi artefak, dengan rumus sebagai berikut:

$$
\sigma^{2} 2=\varrho^{2} \times \tilde{A}^{2} \times \mathrm{V}=(0,679)^{2} \times(0,916)^{2} \times 0,0027=0,001
$$

Varians korelasi sesungguhnya dihitung berdasarkan rumus berikut:

$$
\begin{gathered}
\operatorname{Var}(\mathrm{p})=\left(\operatorname{Var}\left(\mathrm{p}_{\mathrm{xy}}\right)-\mathrm{Q}^{2} \times \tilde{A}^{2} \times \mathrm{V}\right) / \tilde{A}^{2}=(0,01551-0,001) / 0,916^{2}=0,017293 . \\
\mathrm{SD}=\sqrt{0,017293}=0,132
\end{gathered}
$$


Interval kepercayaan :

$\mathrm{p} \pm 1,96 \mathrm{SD}$

$\mathrm{p}+1,96 \mathrm{SD}=0,679+(1,96 \times 0,132)=0,938 ;$ dan

$\mathrm{p}-1,96 \mathrm{SD}=0,679-(1,96 \times 0,132)=0,420$

Dampak variasi reliabilitas sebesar:

$=\left(\mathrm{Q}^{2} \times \tilde{A}^{2} \times \mathrm{V}\right) / \sigma_{\mathrm{r}}^{2} \times 100 \%=0,001 / 0,018 \times 100 \%=5,56 \%$

\section{B. Hasil}

Studi meta analisis menemukan bahwa korelasi populasi yang sesungguhnya (p) setelah dikoreksi oleh kesalahan pengukuran diestimasikan sebesar 0,679, varians populasi [Var(p)] sebesar 0,0172930, dengan standar deviasinya (SD) sebesar 0,132. Mengacu pada interval kepercayaan 95\%, batas penerimaannya antara 0,420 < p < 0,938 ; dan hasil perhitungan (p) sebesar 0,679, ini berarti masuk dalam batas interval penerimaan.

Selanjutnya, ditemukan koefisien korelasi populasi setelah dikoreksi dengan jumlah sampel atau ř sebesar 0,622, varians korelasinya [ $\sigma 2 r]$ sebesar 0,018 dengan standar deviasi (SD) sebesar 0,16. Mengacu pada interval kepercayaan sebesar 95\%, batas penerimaannya antara $0,359<\breve{\mathrm{r}}<0,885$. Dengan demikian hasil perhitungan $\breve{\mathrm{r}}$ sebesar 0,622 berada pada batas penerimaan.

Berdasarkan hasil ini maka dapat disimpulkan bahwa hipotesis yang menyatakan adanya hubungan antara TQM dan kinerja organisasi dapat diterima.

Aspek lain yang perlu diperhatikan dan dikaji lebih lanjut pada studi meta analisis mengenai hubungan antara TQM dan kinerja organisasi, adalah tentang kesalahan dalam pengambilan sampel dan kesalahan dalam pengukuran. Berdasarkan perhitungan diperoleh hasil sebagai berikut ini:

1. Kesalahan dalam pengambilan sampel

Nilai varians kesalahan pengambilan sampel adalah sebesar 0,00249 dan varian korelasi populasi sebesar 0,018. Nilai varians kesalahan pengambilan sampel dibandingkan dengan nilai varians korelasi populasi dikalikan $100 \%$ merupakan hasil bahwa persentase varians yang disebabkan kesalahan pengambilan sampel adalah relatif kecil, yaitu sebesar $13,8 \%$. Persentase ini menunjukkan bahwa bias kesalahan karena kekeliruan dalam pengambilan sampel adalah kecil.

2. Kesalahan dalam pengukuran

Nilai varians kesalahan pengukuran pada variabel dependen adalah sebesar 0,001 dan nilai varian korelasi populasi 0,018. Apabila variansi kesalahan pengukuran dibandingkan dengan varians korelasi populasi, maka persentase variansi yang disebabkan kesalahan pengukuran adalah kecil, yaitu 5,56\%; lebih kecil dari dampak kesalahan pengambilan sampel. Persentase yang kecil ini menunjukkan bias kesalahan karena kekeliruan dalam pengukuran adalah kecil.

\section{KESIMPULAN DAN SARAN}

Hasil meta analisis ini mendukung penelitian yang sebelumnya mengenai adanya hubungan antara TQM dengan kinerja organisasi. Kinerja organisasi akan meningkat ketika perusahaan menjalankan penerapan peningkatan kualitas yang lebih baik, seperti penerapan Total Quality Management (TQM).

Karakteristik sampel yang diambil dalam penelitian ini sebagian besar melingkupi perusahaan serta Usaha Kecil Menengah (UKM) yang bergerak di bidang manufaktur. Hanya ada terdapat 1 (satu) jenis perusahaan yang bergerak di bidang jasa. Oleh karena itu bagi peneliti selanjutnya dapat memperhatikan karakteristik organisasi yang akan diteliti bagi pengaruhnya terhadap peningkatan kinerja organisasinya. Jenis 
organisasi yang berbeda dapat mempengaruhi proses penerapan peningkatan kualitasnya, sehingga dapat juga mempengaruhi peningkatan kinerjanya.

\section{DAFTAR PUSTAKA}

[1] Jitpaiboon, T., Rao, S.S., 2007, A meta-analysis of quality measures in manufacturing system, , International Journal of Quality \& Reliability Management vol 24 no 1 pp 78-102

*[2] Khan, M. A., 2011, Total Quality Management and Organizational PerformanceModerating Role of Managerial Competencies, International Journal of Academic Research vol 3 no 5

*[3] Abusa, F. M., Gibson, P.,2013, Experiences of TQM elements on organisational performance and future opportunities for a developing country, International Journal of Quality and Reliability Management vol 30, no 9, pp 920-941

[4] Helmi, A.F., 2005, Studi Meta-Analisis: Gaya Kelekatan dan Model Mental Diri, Tugas Mata Kuliah : Metodologi Penelitian Kuantitatif Meta Analisis, Program Pra S3, UGM, tidak dipublikasikan

[5] Hunter, J.E., Schmidt, F.L., 2004, Methods of Meta-analysis $2^{\text {nd }}$ ed, Sage Publication, Inc, United States of America

*[6] Joiner, T. A., 2007, Total quality management and performance, International Journal of Quality \& Reliability Management vol 24 no 6 pp 617-627

*[7] Koc, T., 2011, The Relationship between TQM and Performance in Small Manufacturing Enterprises: The Mediation Effect of Failure, International Journal of Industrial Engineering, 18 (4), 203-218

*[8] Sohail, M.S., Hoong, T.B., 2003, TQM practices and organizational performances of SMEs in Malaysia: Some empirical observations, Benchmarking: An International Journal vol 10 No 1 pp 37-53

*[9] Fotopoulos, C.V., Psomas, E.L., 2010, The structural relationships between TQM factors and organizational performance, The TQM Journal, vol 22 no 5 pp 539-552

*[10] Hasan, M., Kerr, R. M., 2003, The relationship between total quality management practices and organisational performance in service organisations, The TQM Magazine vol 15 No 4 pp 286-291

*[11] Demirbag, M., Koh, L.S.C., Tatoglu, E., Zaim, S., 2006, TQM and market orientation's impact on SME's performance, Industrial Management \& Data Systems, vol 106 no 8 pp 1206-1228

*[12] Jung, J.Y., Hong, S., 2008, Organizational citizenship behaviour (OCB), TQM and performance at the Maquiladora, International Journal of Quality \& Reliability Management vol 25 no 8 pp 793-808

*[13] Valmohammadi, C., 2011, The impact of TQM implementation on the organizational performance of Iranian manufacturing SMEs, The TQM Journal vol 23 no 5 pp 496-509

*[14] Samarakoon, S.M., Jasek, R., Shamil, M., 2012, Market orientation and its' influence on business performance of small and medium sized enterprises, Scientific papers of the University of Pardubice Series D, Faculty of Economics \& Administration vol 17 issue 23 p 98-109

*[15] Talib, F., Rahman, Z., Queshi, M.N., 2013, An empirical investigation of relationship between total quality management practices and quality performance in Indian service companies, International Journal of Quality \& Reliability Management vol 30 no 3 pp 280-318. 